\title{
Analisa Efek Otomatisasi Proses terhadap Kapasitas Produksi dengan Studi Kasus Mesin Selotip Semi Otomatis di Industri Pengemasan
}

\author{
Farika Tono Putri ${ }^{*}$, Galih Luthfiansyah ${ }^{1}$, Ragil Tri Indrawati ${ }^{2}$, Budhi Prasetyo ${ }^{3}$, Slamet Priyoatmojo ${ }^{3}$ \\ ${ }^{1}$ Program Studi Sarjana Terapan Teknik Mesin Produksi dan Perawatan, Politeknik Negeri Semarang \\ ${ }^{2}$ Program Studi Diploma 3 Teknik Mesin, Politeknik Negeri Semarang \\ ${ }^{3}$ Program Studi Diploma 3 Teknik Konversi Energi, Politeknik Negeri Semarang \\ J1. Prof. Sudharto, SH. Tembalang, Indonesia \\ *E-mail: farika.tonoputri@polines.ac.id
}

Diterima: 14-07-2021; Direvisi: 26-07-2021; Dipublikasi: 27-08-2021

\begin{abstract}
Abstrak
Industri kosmetik adalah industri yang bertumbuh dengan sangat pesat. Tumbuhnya industri kosmetik tersebut menjadikan industri lain yang berhubungan dengan kosmetik turut berkembang. Salah satunya yaitu industri pengemsan. Proses penempelan selotip pada layer karton yang masih manual dikerjakan oleh operator dengan alat potong berupa cutter mengakibatkan sebuah industri pengemasan tidak mampu memenuhi permintaan konsumen. Pada penelitian ini dikembangkan sebuah mesin selotip semi otomatis dengan harga yang murah dan mudah dioperasikan. Tujuan dari penelitian ini adalah meningkatkan kapasistas produksi melalui penggantian metode produksi dari konvensional ke semi otomatis. Hasil penelitian menunjukkan efektifitas cycle time sebesar $72 \%$ dengan mesin selotip semi otomatis. Kapasitas produksi pun naik $118 \%$.
\end{abstract}

Kata kunci: mesin selotip; semi otomatis; industri kemasan

\begin{abstract}
Cosmetic industries are fast growing industry. The growth of cosmetic industry affect the development of other industries related to cosmetic. One of those industry is packaging industry. The process of pasting the tape on the cardboard layer which is still manually done by the operator with a cutting tool in the form of a cutter has resulted in an industry not being able to meet consumer demand. In this study, a semi-automatic tape machine was developed with a low price and easy to operate. The purpose of this research is to increase production capacity by changing production methods from conventional to semi-automatic. The results showed the effectiveness of the cycle time of $72 \%$ with a semi-automatic masking tape machine. Production capacity also increased by $118 \%$.
\end{abstract}

Keywords: semi automatic; tape machine; packaging industry

\section{Pendahuluan}

Industri kosmetik merupakan industri yang bernilai ratusan juta dolar. Data yang dicatatkan oleh Kementrian Perindustrian Indonesia (Kemenperin) menunjukkan ekspor produk kosmetik Indonesia mencapai 600 juta USD pada tahun 2019. Angka tersebut menunjukkan peningkatan bila dibandingkan dengan capaian pada tahun 2018 yaitu sebesar 556,36 juta USD [1]. Pertumbuhan industri kosmetik tersebut mendorong industri lain yang berkaitan dengan kosmetik untuk turut berkembang. Salah satu industri tersebut adalah industri pengemasan kosmetik. Data Indonesia Packaging Federation menunjukkan bahwa kinerja industri kemasan diproyeksikan bertumbuh dengan kisaran $6 \%$ pada tahun 2020 dari nilai realisasi 2019 yang sebesar 98,8 triliyun rupiah [2]. Bertumbuhnya kinerja tersebut menuntut industri kemasan kosmetik untuk selalu produktif dalam melayani permintaan konsumen.

Sebuah industri kemasan kosmetik yang terletak di daerah Kabupaten Semarang memiliki departemen assembly dan packaging yang bertugas untuk mengemas produk akhir berupa kemasan kosmetik ke dalam kardus. Pengemasan tersebut ditujukan untuk pengiriman kepada pelanggan di luar negeri. Kardus yang digunakan berupa layer karton dengan tipe single wall D Flute ketebalan $2 \mathrm{~mm}$. Terdapat beberapa proses yang harus diakukan oleh operator pada layer karton sebelum digunakan sebagai pembatas. Proses tersebut antara lain pemberian selotip pada sekeliling layer 
karton serta penambahan double face tape (DFT) pada permukaan. Pemberian lapisan selotip tersebut bertujuan agar serpihan sekeliling boks tidak masuk dan terurai ke dalam boks yang mengakibatkan produk terkontaminasi oleh serpihan karton sehingga dapat mempengaruhi kualitas produk saat dilakukan pengemasan. Penempelan selotip tersebut masih dilakukan secara manual. Gambar 1 menunjukkan penempelan selotip secara manual di industri kemasan kosmetik.

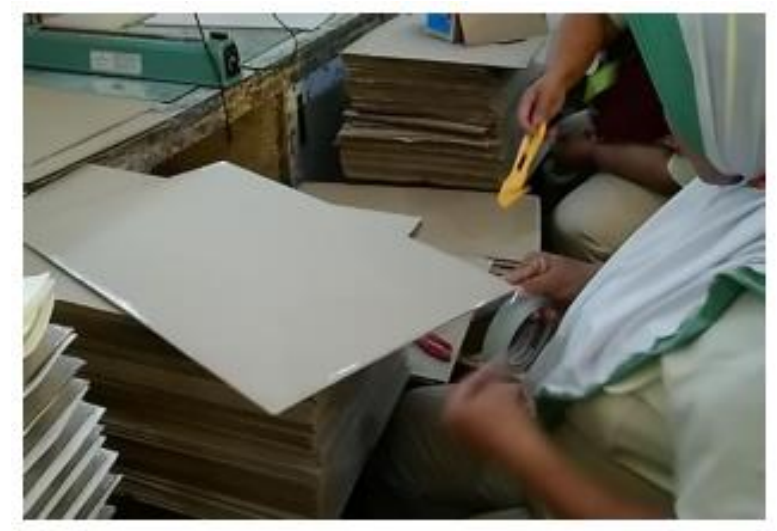

Gambar 1. Proses penempelan selotip yang masih manual oleh operator pada industri kemasan kosmetik

Berdasarkan data operator pada section packing, kapasitas saat ini adalah 1200 buah karton/hari dengan 1 operator yang bekerja dengan sistem 3 shift. Gambar 1 menunjukkan kondisi kerja operator yaitu operator mengambil boks karton yang disediakan oleh Production Planning and Inventory Control (PPIC). Selanjutnya operator menempel selotip pada sekeliling layer karton menggunakan guntung sebagai pemotong. Setelah operator selesai menempelkan selotip sebanyak target yang dibutuhkan, selanjutnya operator akan melakukan proses lainnya yaitu menempelkan DFT, membungkus layer karton dan memotong bungkus layer karton agar rapi. Proses yang seluruhnya masih manual tersebut membuat target produksi belum tercapai.

Selotip atau adhesive tape banyak dipilih sebagai pengaman dalam pengemasan karena adhesive tape merupakan teknologi yang murah, perawatan yang lebih mudah dibandingkan dengan lem panas dan mempunyai produktivitas yang tinggi apabila dilakukan dengan mesin [3]. Otomatisasi dan perancangan mesin selotip telah banyak dikembangkan dan diaplikasikan di industri baik skala kecil, menengah maupun besar. Beberapa mesin selotip yang dikembangkan dan dijual antara lain operator fed fix adjustable dimana dapat digunakan untuk menempelkan selotip pada karton dengan ukuran yang seragam. Dibutuhkan operator untuk melipat karton sebelum karton masuk ke dalam mesin [4]. Kemudian ada pula mesin dengan skala besar yaitu 3M-Matic case sealing system dengan spesifikasi ribuan karton per jam [5]. Mesin-mesin tersebut merupakan mesin dengan harga yang mahal dan hanya dijual di luar negeri dengan ukuran ergonomi operator luar negeri. Pada penelitian ini, mesin selotip semi otomatis yang dihasilkan merupakan mesin dengan harga yang murah, mudah dalam penggunaan dan sesuai dengan ergonomi operator Indonesia.

Peningkatan produktifitas dapat dicapai melalui beberapa metode, antara lain: (i) Mengurangi tenaga kerja, (ii) Penghematan biaya utilitas, (iii) Peningkatan kualitas melalui manajemen kontrol yang baik, (iv) Intensitas produksi yang tinggi dengan mesin-mesin terbaru dan (v) Pencatatan data yang disiplin dengan sebuah sistem. Seluruh metode tersebut akan dapat dijalankan apabila sistem otomasi diimplemetasikan [6]. Sebuah penelitian menunjukkan implementasi sistem otomasi pada industri manufaktur dapat meningkatkan produktivitas dan kualitas produk [7-10]. Penelitian lain yang dilakukan berkaitan dengan otomasi yaitu pada sebuah assembly line manual. Sebuah assembly line 
Farika Tono Putri dkk /Jurnal Rekayasa Mesin

p-ISSN: 1411-6863, e-ISSN: 2540-7678

Vol.16, No.2, Agustus 2021, hal. 286-297

dengan bentuk parallel single stage dan assembly line dengan bentuk serial lima stage diambil sebagai sebuah studi kasus. Hasil menunjukkan bahwa assembly line menghasilkan produktivitas yang meningkat [11]. Penelitian lain menunjukkan implementasi sistem otomasi berupa Elipse SCADA dengan metode Structured Analysis-Real Time (SART) pada sebuah mesin thermal shrink packaging. Implementasi SCADA disertai dengan perancangan Human-Machine Interface (HMI) yang efektif dapat meningkatkan produktivitas produksi, meminimalisir bahan-bahan terbuang dan overwork pada mesin [12]. Dengan penerapan mesin selotip semi otomatis pada penelitian ini diharapkan produktivitas kemasan semakin meningkat dan dapat memenuhi kebutuhan konsumen.

\section{Material dan metodologi}

Penelitian dan pengujian alat mengambil sebuah studi kasus pada industri pembuatan kemasan kosmetik yang terletak di Kabupaten Semarang, Jawa Tengah, Indonesia. Metode yang dilakukan dalam penelitian ini yaitu: (i) Menentukan spesifikasi mesin yang akan dibuat, (ii) Membuat beberapa desain mesin dengan menggunakan software Computer Aided Design (CAD), (iii) Melakukan pemilihan desain mesin yang akan dibuat, (iv) Pembuatan mesin dan (v) Pengujian mesin.

Penentuan spesifikasi mesin dilakukan berdasarkan wawancara dengan operator sehingga menghasilkan karakteristik mesin yang diinginkan seperti cara kerja mesin, ukuran mesin, keamanan mesin, cycle time penempelan selotip yang ditargetkan dan kapasitas produksi yang ditargetkan. Ukuran mesin dipengaruhi oleh spesifikasi karton yang digunakan. Gambar 2 menunjukkan jenis karton yang digunakan dan Tabel 1 merupakan kode nama karton yang digunakan dalam pengemasan beserta ukuran dalam satuan $\mathrm{mm}$. Jenis karton yang diguakan untuk pengemasan adalah corrugated box, yaitu kardus yang bergelombang yang dapat melindungi produk dari benturan selama proses pengiriman.

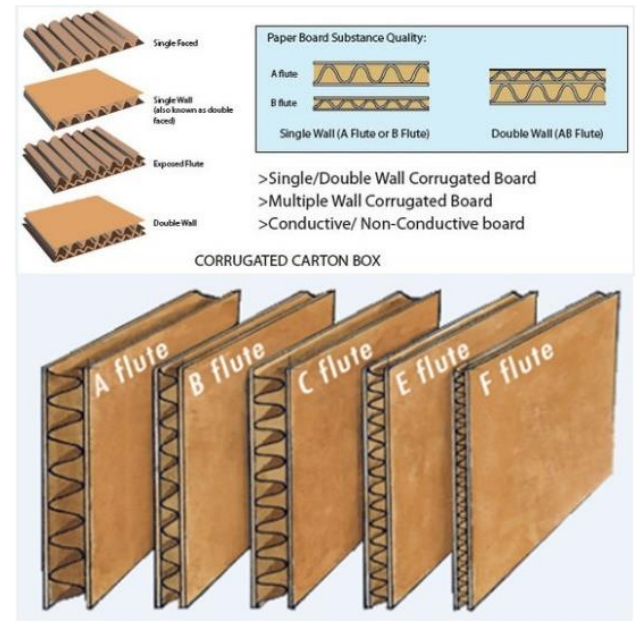

Gambar 2. Jenis karton yang digunakan untuk pengemasan [13]

Tabel 1. Kode nama dan ukuran karton [14]

\begin{tabular}{|c|c|}
\hline Kode Karton & Ukuran (panjang $\mathrm{x}$ lebar) (mm) \\
\hline PT21 & $445 \times 295$ \\
\hline PT51 & $470 \times 340$ \\
\hline PT55 & $540 \times 355$ \\
\hline
\end{tabular}




\begin{tabular}{ll}
\hline PT64 & $375 \times 375$ \\
CM257 & $560 \times 355$ \\
CM258 & $525 \times 325$ \\
CM263 & $225 \times 223$ \\
CM272 & $535 \times 335$ \\
FP14 & $440 \times 300$ \\
\hline
\end{tabular}

\section{Hasil dan pembahasan}

Desain yang dibuat dalam penelitian ini terdiri dari 3 buah rancangan yang berbeda. Tabel 2 merupakan matriks morfologi untuk desain mesin selotip semi otomatis dimana akan dapat disusun beberapa varian alternatif konsep desain yang mungkin dibuat. Matriks morfologi merupakan pengembangan dari blok fungsi menjadi beberapa sub fungsi, sub fungsi dikembangkan lagi menjadi beberapa sub-sub fungsi. Sub-sub fungsi terdiri dari material, komponen penggerak, dan mekanisme. Setelah menetapkan sub-sub fungsi, selanjutnya membuat opsi-opsi dari sub-sub fungsi yang diberi kode A1, B1, B2, B3 dan seterusnya [15].

Tabel 2. Matriks morfologi alternatif desain mesin selotip semi otomatis

\begin{tabular}{clll}
\hline No & Sub Fungsi & \multicolumn{1}{c}{ Sub-sub Fungsi } & \multicolumn{1}{c}{ Sub Sub-sub Fungsi } \\
\hline 1 & Pemilihan material utama & Material & (A1) Poly Ethylene (PE) \\
& & & (A2) Aluminium \\
2 & Sistem gerak angkat & Mekanisme & (B1) Ulir \\
& & & (B2) Rack and Pinion \\
3 & Penggerak angkat & Mekanisme & (B3) Fixed Slider \\
& & & (C1) Manual \\
4 & Motor Roller & Jumlah & (C2) Motor \\
& & & (D1) Satu buah \\
\end{tabular}

Desain alternatif 1 ditunjukkan pada Gambar 3 dimana konsep matriks morfologi sesuai Tabel 2 terdiri dari varian (A2), (B2), (C2) dan (D2).

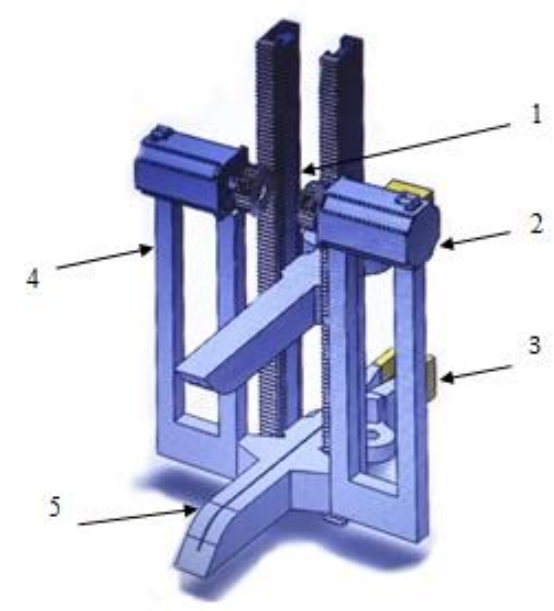


Gambar 3. Alternatif desain 1

Keterangan pada Gambar 3 yaitu: (1) Rack and pinion, (2) motor, (3) Jig depan, (4) Rangka dan (5) Jig base. Alternatif desain 1 menyajikan desain dengan material alumunium pada jig dan rangka. Sistem gerak angkat menggunakan motor pada kedua pilar agar dapat mengangkat jig dengan seimbang. Motor tersebut terhubung dengan mekanisme rack and pinion pada komponen nomor (1) yang berfungsi sebagai transimisi untuk mengangkat jig bagian atas. Jumlah motor yang digunakan untuk menggerakkan roller sebanyak dua buah. Komponen nomor (3) merupakan jig depan yang berfungsi untuk menekuk selotip agar tertempel di ujung sisi layer karton.

Gambar 4 merupakan desain alternatif 2 dengan konsep matriks morfologi (A1), (A2), (B3), (C1) dan (D2). Material yang digunakan ada 2 jenis yaitu PE dan Aluminium. Aluminium digunakan pada rangka seperti yang ditunjukkan pada nomor (2) dan bagian slider pada komponen nomor (5). Sedangkan untuk bagian jig-nya menggunakan material PE sesuai yang ditunjukkan nomor (4). Kemudian untuk penggerak masing-masing roller terdapat motor yang ditunjukkan oleh nomor (3). Komponen nomor (1) adalah posisi layer karton saat menggunakan mesin ini. Pada alternatif desain ini sistem gerak angkatnya menggunakan metode secara manual yaitu diangkat secara langsung menggunakan tangan lalu dikunci pada masing-masing slider. Keterangan komponen pada Gambar 5 antara lain: (1) Layer karton, (2) Rangka, (3) Motor roller, (4) Jig depan dan (5) Slider.

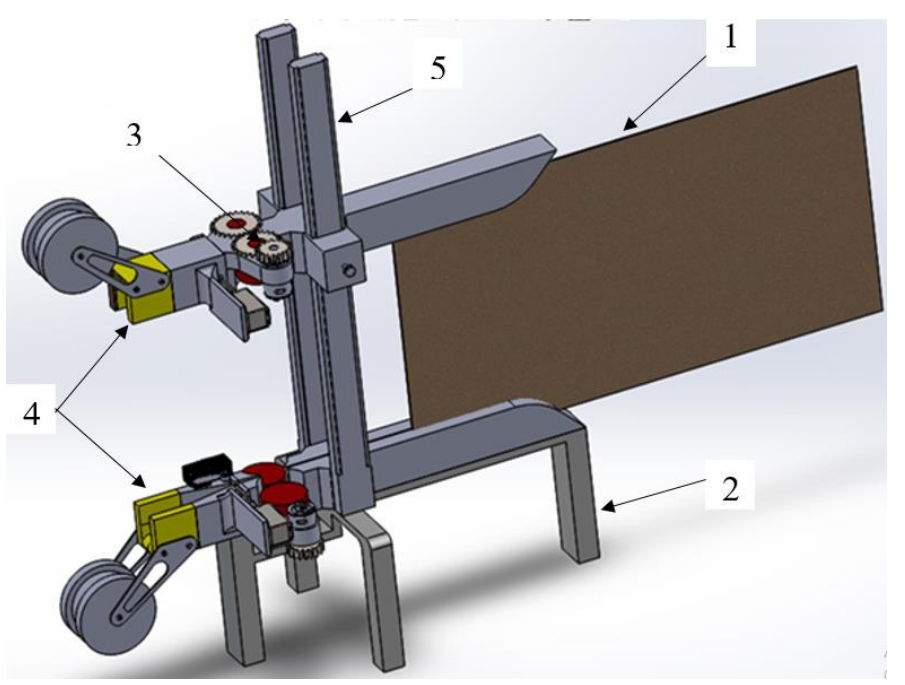

Gambar 4. Alternatif desain 2

Alternatif desain 3 ditunjukkan pada Gambar 5 menyajikan desain dengan konsep matriks morfologi (A1), (A2), (B1), (C1) dan (D1). Keterangan Gambar 5 yaitu: (1) Screw, (2) Motor roller, (3) Jig depan dan (4) Slider. Material PE digunakan pada bagian jig seperti yang ditunjukkan nomor (3). Fungsi pada bagian jig menggunakan material PE yaitu untuk mempermudah dalam proses pembuatan dan memiliki material yang relatif ringan. Sedangkan untuk rangkanya menggunakan material alumuniun seperti yang ditunjukkan pada nomor (4). Selain itu pada alternatif ini menggunakan 1 motor untuk penggerak roller yang ditunjukkan pada nomor (2). Konsep desain ini memanfaatkan mekanisme ulir atau screw sebagai pengangkat jig bagian atas yang ditunjukkan oleh nomor (1). Penggunaan screw sebagai pengangkat jig ini dinilai lebih presisi dan imbang saat digunakan. 


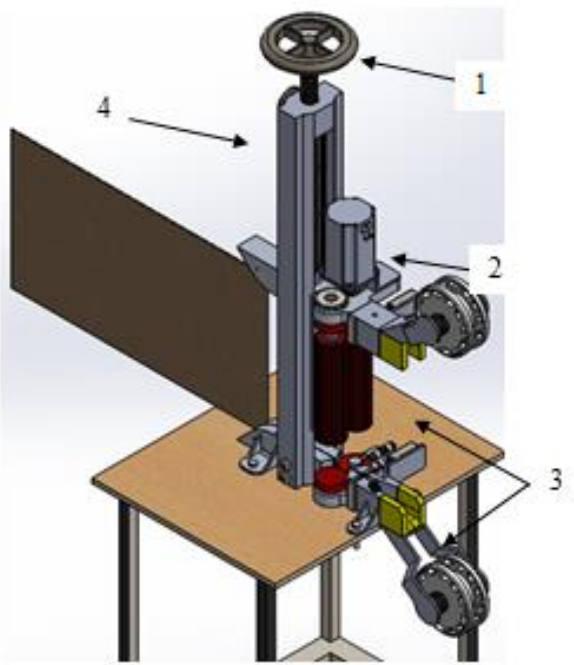

Gambar 5. Alternatif desain 3

Pemilihan desain dilakukan berdasarkan pembobotan kriteria dan penilaian yang ditunjukkan pada Tabel 3 dan Tabel 4. Pembobotan dilakukan dengan memberikan nilai untuk masing-masing kriteria. Tabel 3 merupakan kriteria seleksi desain mesin selotip semi otomatis. Kriteria tersebut terdiri dari Kemudahan perawatan mesin (maintenance), fungsi mesin, keamanan mesin (safety) dan ergonomi mesin. Dari kriteria tersebut kemudian dilakukan pembobotan untuk menentukan urutan kriteria mulai dari yang lebih proritas sampai dengan kurang prioritas. Nilai 1 diberikan jika kriteria satu lebih prioritas dibandingkan kriteria lainnya, nilai 0 diberikan jika kriteria satu kurang prioritas dibanding kriteria lainnya dan nilai 0,5 diberikan jika kedua kriteria sama tingkat prioritas.

Tabel 3. Bobot penilaian kriteria seleksi desain mesin selotip semi otomatis

\begin{tabular}{lccccc}
\hline \multicolumn{1}{c}{ Kriteria } & A & B & C & D & Total Nilai \\
\hline Maintenance & - & 0 & 0 & 0,5 & 0,5 \\
Fungsi mesin & 1 & - & 0,5 & 0,5 & 2 \\
Safety & 1 & 0,5 & - & 1 & 2 \\
Ergonomi mesin & 1 & 0,5 & 0 & - & 1,5
\end{tabular}

Keterangan:

$\begin{array}{ll}\text { A } & \text { : Maintenance } \\ \text { B } & : \text { Fungsi mesin } \\ \text { C } & : \text { Safety } \\ \text { D } & : \text { Ergonomi mesin }\end{array}$

Pembobotan kriteria menghasilkan urutan kriteria mulai dari yang paling prioritas yaitu: Fungsi mesin, safety, ergonomi mesin dan maintenance mesin. Tabel 4 adalah matrik keputusan untuk pemilihan konsep desain. Masingmasing konsep alternatif desain diberikan penilaian berdasarkan kriteria. Nilai masing-masing desain berkisar antara 110 dimana semakin besar nilai maka semakin baik desain tersebut terhadap kriteria. Kolom bobot diambil dari kolom total nilai pada Tabel 3. Kolom nilai keputusan diambil dari bobot dikalikan dengan kolom nilai alternatif desain. 
Farika Tono Putri dkk /Jurnal Rekayasa Mesin

p-ISSN: 1411-6863, e-ISSN: 2540-7678

Vol.16, No.2, Agustus 2021, hal. 286-297

Tabel 4. Pemilihan konsep berdasarkan matriks keputusan

\begin{tabular}{lccccccc}
\hline \multicolumn{1}{c}{ Kriteria } & Bobot & \multicolumn{3}{c}{ Nilai Alternatif Desain } & \multicolumn{3}{c}{ Nilai Keputusan } \\
& & $\mathbf{1}$ & $\mathbf{2}$ & $\mathbf{3}$ & $\mathbf{1}$ & $\mathbf{2}$ & $\mathbf{3}$ \\
\hline Fungsi mesin & 2 & 8 & 7 & 9 & 16 & 14 & 18 \\
Safety & 2 & 8 & 8 & 8 & 16 & 16 & 16 \\
Ergonomi & 1,5 & 7 & 8 & 9 & 10,5 & 12 & 13,5 \\
Maintenance & 0,5 & 8 & 9 & 9 & 4,5 & 4,5 \\
& & & Total Nilai Keputusan & 46,5 & 46,5 & 52 \\
\hline
\end{tabular}

Berdasarkan hasil matriks keputusan maka desain yang paling layak untuk dilakukan pembuatan adalah alternatif desain 3. Tabel 5 adalah bagian-bagian detail dari alternatif desain 3.

Tabel 5. Bagian-bagian detail dari alternative desain 3

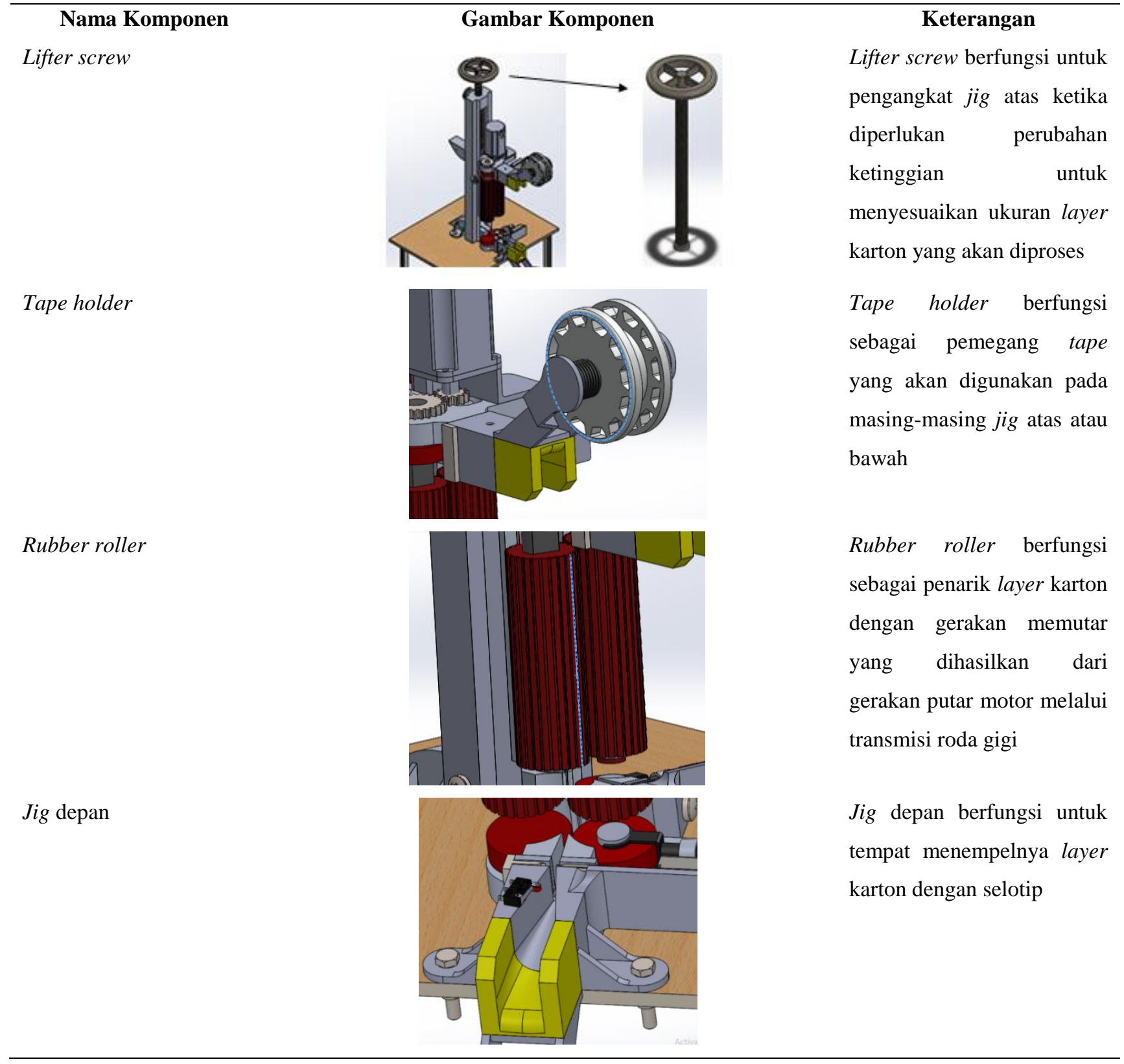


Farika Tono Putri dkk /Jurnal Rekayasa Mesin

p-ISSN: 1411-6863, e-ISSN: 2540-7678

Vol.16, No.2, Agustus 2021, hal. 286-297

Slider

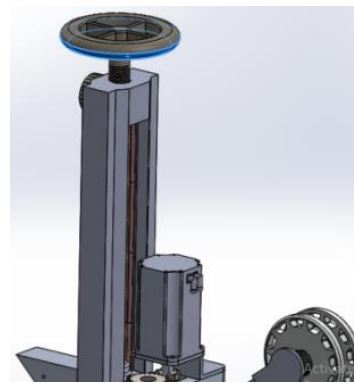

Slider berfingsi sebagai rangka dan jalur jig atas ketika diangkat

Jig base

Transmisi
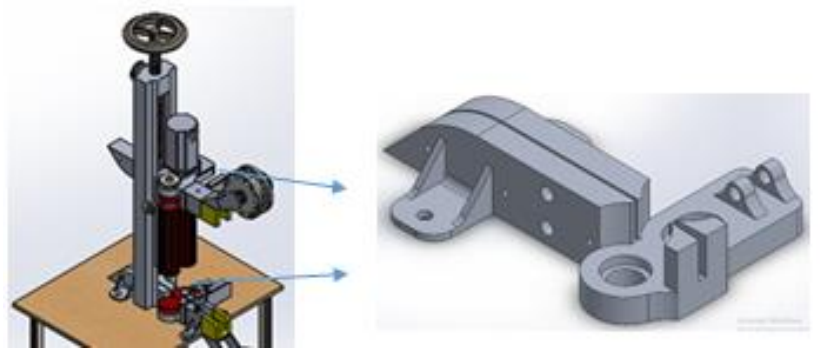

Jig base berfungsi sebagai jalur layer karton ketika diproses

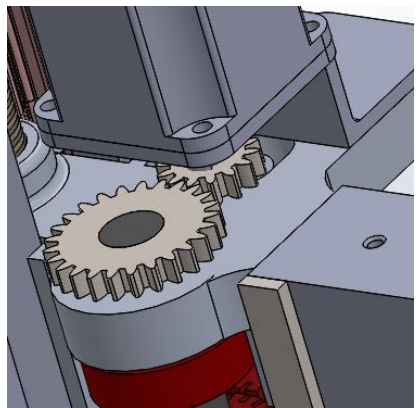

Transmisi yang dipasang berupa roda gigi dengan jumlah gigi 10 untuk roda gigi dari motor dan jumlah gigi 20 untuk gigi poros rubber roller

Motor sinkron

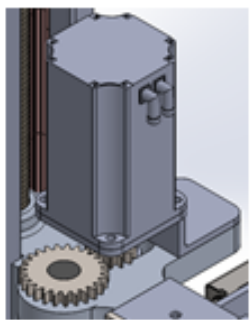

Jenis motor yang digunakan pada mesin selotip semi otomatis ini menggunakan jenis motor sinkron

Solenoid door lock

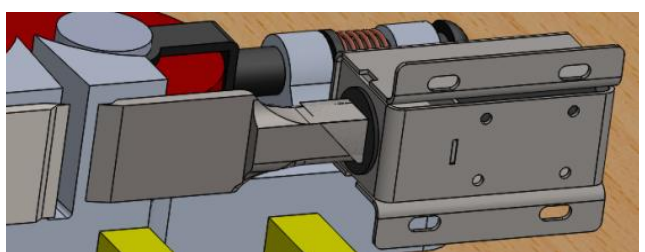

Solenoid door lock pada mesin ini digunakan sebagai pendorong pisau yang berfungsi untuk memotong selotip secara otomatis 
Farika Tono Putri dkk /Jurnal Rekayasa Mesin

p-ISSN: 1411-6863, e-ISSN: 2540-7678

Vol.16, No.2, Agustus 2021, hal. 286-297

Limit switch

Setelah desain terpilih maka selanjutnya dilakukan pembuatan mesin selotip semi otomatis. Gambar 6 menunjukkan proses pengoperasian dan pengujian mesin.

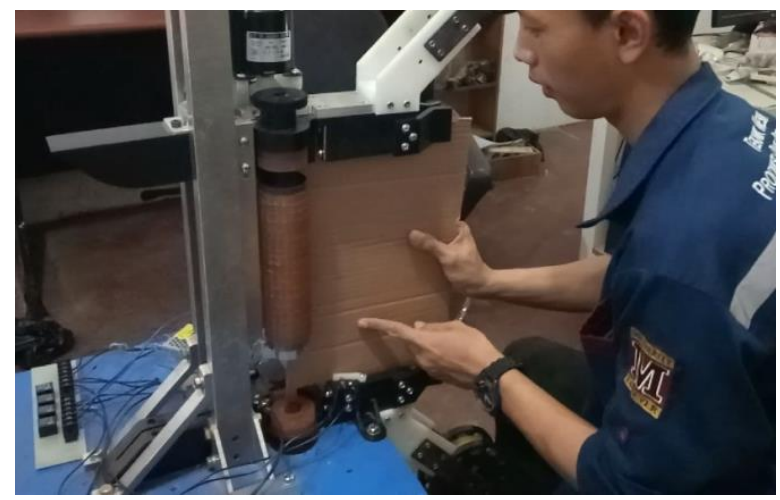

Gambar 6. Proses pengoperasian mesin

Pengujian pertama yang dilakukan yaitu pengujian kualitas hasil penempelan selotip. Standar kriteria kualitas yaitu visual bersih tidak terdapat serpihan karton, penempelan selotip merata, tidak merusak permukaan layer karton, penurunan ketebalan layer karton maksimal $2 \mathrm{~mm}$ dan pemotongan selotip rapi. Gambar 7 (a) menunjukkan layer karton setelah penempelan selotip dan (b) kerataan penempelan selotip. Tabel 6 adalah ketebalan layer karton sebelum proses penempelan selotip dan setelah proses penempelan selotip. Pengurangan ketebalan kurang dari $2 \mathrm{~mm}$ yang berarti pengujian visualisasi masih sesuai dengan standar.
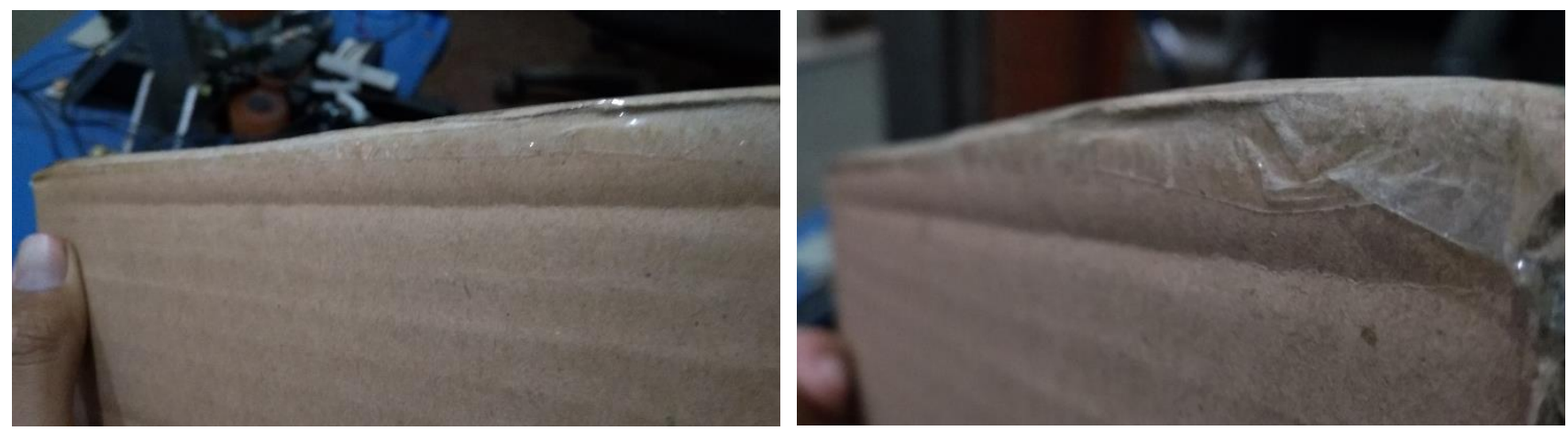

Gambar 7. (a) Layer karton setelah penempelan selotip dan (b) Kerataan penempelan selotip 
Farika Tono Putri dkk /Jurnal Rekayasa Mesin

p-ISSN: 1411-6863, e-ISSN: 2540-7678

Vol.16, No.2, Agustus 2021, hal. 286-297

Tabel 6. Ketebalan layer karton sebeum dan setelah proses

\begin{tabular}{cccc}
\hline Pengujian ke- & Ketebalan sebelum Proses $(\mathbf{m m})$ & Ketebalan setelah Proses (mm) & Status \\
\hline 1 & 2,1 & 2 & $G O O D$ \\
2 & 2 & 2 & $G O O D$ \\
3 & 2 & 1,99 & $G O O D$ \\
4 & 1,98 & 1,97 & $G O O D$ \\
5 & 2,1 & 2,1 & $G O O D$ \\
\hline
\end{tabular}

Pengujian kedua yaitu pengujian cycle time untuk tipe CM257, CM267 dan FP14. Tabel 7 adalah perbedaan cycle time penempelan selotip dengan metode manual yaitu operator menempel dan memotong dengan selotip dan penempelan dengan mesin.

Tabel 7. Perbandingan cycle time tipe CM257

\begin{tabular}{ccccccc}
\hline $\begin{array}{c}\text { Pengujian } \\
\text { ke- }\end{array}$ & \multicolumn{2}{c}{$\begin{array}{c}\text { Cycle Time (detik) Tipe } \\
\text { CM257 }\end{array}$} & \multicolumn{2}{c}{$\begin{array}{c}\text { Cycle Time (detik) Tipe } \\
\text { CM267 }\end{array}$} & \multicolumn{2}{c}{ Cycle Time (detik) Tipe FP14 } \\
& Before & After & Before & After & Before & After \\
\hline 1 & 24,61 & 8,99 & 25,67 & 4,53 & 26,19 & 7,19 \\
2 & 25,27 & 8,71 & 24,11 & 4 & 25,54 & 7,82 \\
3 & 26 & 9,14 & 25,52 & 5,1 & 25,27 & 6,94 \\
4 & 24,93 & 9,07 & 25,1 & 4,85 & 26,22 & 8 \\
5 & 25,91 & 9,03 & 23,95 & 4,12 & 25,31 & 7,67 \\
Rata-rata & 25,3 & 9 & 24,86 & 4,52 & 25,7 & 7,52 \\
\hline
\end{tabular}

Hasil pengujian pada Tabel 7 menunjukkan adanya penurunan cycle time. Penurunan cycle time tersebut berbanding lurus dengan peningkatan kapasitas produksi. Tabel 8 merupakan hasil kenaikan beberapa variabel dengan adanya mesin selotip semi otomatis ini. Variabel kenaikan dilihat dari efisiensi cycle time, peningkatan kapasitas produksi, pengurangan manpower dan faktor keamanan operator.

Tabel 8. Potensial benefit dari penggunaan mesin selotip semi otomatis

\begin{tabular}{|c|c|c|c|c|c|}
\hline No & Variabel & Before & After & Selisih & Efisiensi \\
\hline 1 & Cycle time & $25 \mathrm{detik} / \mathrm{buah}$ & 7 detik/buah & 18 detik & $72 \%$ \\
\hline \multirow[t]{3}{*}{2} & Kapasitas & 975 buah/shift & 2127 buah/shift & 1152 buah/shift & $118,1 \%$ \\
\hline & produksi & 2925 buah/hari & $6381 \mathrm{buah} / \mathrm{shift}$ & 3456 buah/shift & \\
\hline & & 70200 buah/bulan & $163144 \mathrm{buah} / \mathrm{shift}$ & 82944 buah/shift & \\
\hline 3 & Man power (MP) & $3 \mathrm{MP} / \mathrm{hari}$ & $2 \mathrm{MP} / \mathrm{hari}$ & $1 \mathrm{MP} /$ hari & $33,33 \%$ \\
\hline 4 & Safety & $\begin{array}{l}\text { Kurang safety, operator } \\
\text { menggunakan cutter } \\
\text { dengan tangan langsung }\end{array}$ & $\begin{array}{l}\text { Lebih safety karena } \\
\text { pemotong semi otomatis } \\
\text { dan jauh dari tangan } \\
\text { operator }\end{array}$ & Safety meningkat & \\
\hline
\end{tabular}




\section{Kesimpulan}

Usaha otomatisasi dan penggantian proses produksi kearah yang lebih modern akan sangat menguntungkan bagi sebuah industri. Dalam penelitian ini industri yang dijadikan studi kasus adalah industri pengemasan. Dengan penggunaan mesin-mesin otomatis atau semi otomatis maka kapasitas produksi akan semakin meningkat. Akibat dari kapasitas produksi yang meningkat, industri akan sanggup memenuhi permintaan konsumen dalam jumlah yang lebih banyak. Hal ini sangat menguntungkan terutama bagi industri dengan permintaan tinggi. Selain dilihat dari sisi produksi, penggunaan mesin modern akan meningkatkan keamanan bagi operator.

\section{Daftar Pustaka}

[1] Huda, Larisa. Perubahan gaya hidup dorong industri kosmetik. https://koran.tempo.co/read/ekonomi-danbisnis/449594/perubahan-gaya-hidup-dorong-industri-kosmetik. Indonesia: Tempo; 2020 (Diakses pada tanggal 24 Maret 2021).

[2] Kementrian Perindustrian Indonesia. Kemenperin poles kualitas desain kemasan IKM kosmetik. https://kemenperin.go.id/artikel/21997/Kemenperin-Poles-Kualitas-Desain-Kemasan-IKM-Kosmetik. Indonesia: Kemenperin; 2020 (Diakses pada tanggal 24 Maret 2021).

[3] Al-Helou, H., Goman, D., dan Shojayan, S. Tape machine in packaging: A study of safety impacts. Swedia: University of Boras; 2018. pp. 18.

[4] Industrial Packaging Corporation. Industrial packaging equipment: Tape machines. https://industrialpack.com/equipment/tape-machines/. Amerika: Industrial Packaging Corporation; 2020 (Diakses pada tanggal 24 Maret 2021).

[5] 3M Industrial Adhesives and Tapes. 3M Instruction and parts list. https://multimedia.3m.com/mws/media/9421630/3m-matic-case-sealer-200a-owners-manual-north-america.pdf. Amerika: 3M Industrial Adhesives and Tapes; 2011. pp. 20.

[6] Nimawat, Dheeraj dan Shrivastava, A. Increasing productivity through automation. European Journal of Advances in Engineering and Technology. 2016: 3(2). pp. 45-47.

[7] Chaudari, Niraj C., Patii, Pavitra D., Chaudari, Mayur R., Lanje, Pankaj K., dan More, Mayur S. Increasing productivity and quality of products by implementations of automation in manufacturing sectors. International Journal of Advance Research, Ideas and Innovations in Technology. 2017: 3(2). pp. 9-12.

[8] Sima, V., Gheorge, I.G., Subic, J. dan Nancu, D. Influences of the industry 4.0 revolution on the human capital development and consumer behavior: A systematic review. Sustainability MDPI. 2020: 12(4035). pp. 1-28.

[9] Vermeulen, B., Kesselhut, J., Pyka, A. dan Saviotti, P.P. The impact of automation on employment: Just the usual structural change. Sustainability MDPI. 2018: 10(1661). pp. 1-27.

[10] Kokkonen, T. The impact of automation and robotization on income distribution in post industrial countries: Who are the winners and what steps should society take?. Finlandia: Aalto University School of Business; 2016. pp. 3840.

[11] Yerasi, Pranavi. Productivity improvement of a manual assembly line. Amerika: Texas A\&M University; 2011. pp. 50.

[12] Schluter, Melissa D., Izquerdo, Rafael C., Medina, Betania O., Rosa, Guilherme C., dan Toso, Marcelo A. . Modelling and implementation of automation system applying project methodologies-Thermal shrink packaging machine. Applied Mechanics and Material. 2015: 727-728. pp. 740-745. 
p-ISSN: 1411-6863, e-ISSN: 2540-7678

Vol.16, No.2, Agustus 2021, hal. 286-297

[13] Caballero-Jimenez, M.A., Conde, I., Garcia,B dan Liarte, E. Design of different type of corrugated board packages using finite element tools. Proceeding of SIMULIA Customer Conference. Simulia.com; 2009.

[14] PT. Techpack Asia. Daftar kode layer karton. Semarang: PT. Techpack Asia; 2020.

[15] Cheng, Jinxia. Product design process and methods. IntechOpen; 2018. pp. 25-30. 